\title{
Painting in Extreme Environments
}

\section{Dr Marianne Greated}

Painting and Printmaking Department, The Glasgow School of Art, Glasgow, UK

Email:m.greated@gsa.ac.uk 


\title{
Painting in Extreme Environments
}

\begin{abstract}
The way in which sound and vision work together within the context of art has been explored through experiments and public exhibitions of paintings in the extreme sonic environments of anechoic and reverberation chambers. The work was in the form of individual paintings in the anechoic chambers and painted panoramas in the reverberation rooms and these were accompanied by surround soundscapes all relating to representations of our contemporary environment. The studies support the assertion that the sound within painting installations can change the way in which one experiences the visual art. The overall sensory environment significantly affects the way in which a 'viewer' interprets and responds to the work and expands the scope of the painting.
\end{abstract}

Key Words: Painting, panorama, sound, anechoic, reverberation, expanded

\section{Introduction}

This study aims to investigate the all-encompassing, spatial and time-based nature of a sonic experience alongside the visual experience of viewing painting. It explores how the installation of painting with soundscapes results in immersive environments that are more than the sum of the parts and that these expand the scope of painting. All painting is situated within its current sound environment (or ambience) and some painting may imply sound through its image (as discussed by David Toop in Sinister Resonance, 2010). However this investigation seeks to understand how painting can actively utilise specific sonic qualities, spatial and temporal, to transform painting and considers both the acoustic environment and how sound is added to this. 
Specifically the work focuses on how the urban environment can be explored through both visual and sound art and how these distinct elements within an installation can affect one another. To do this a number of site-specific installations have been developed, which took the form of a series of paintings and three-dimensional soundscapes brought together in the same space. Extreme acoustic spaces, anechoic and reverberation chambers, and a variety of sound transmissions have been used to investigate this. The work was exhibited to the general public and invited audiences and culminated in a public exhibition with feedback gathered.

The study explores how sound and vision can work together within the context of painting, The hypothesis is that the use of sound within the painting installations can change the way in which one experiences the visual aspects and that the overall sensory environment significantly affects the way in which a 'viewer' interprets the work. The term 'viewer' has been used throughout due to the visual art context of the work and as a term often used to describe audio-visual audience members (Chion, 1994), however the 'encounterer' or the 'participant' would be equally valid and draw attention to the expanded nature of the work.

\section{Installations in Extreme Acoustic Spaces}

It is known from previous psychoacoustic tests [Shams et al, 2004; Greated, 2009] that the sonic environment in a space affects the way in which visual images are viewed. As stated by Calvert, Spence and Stein, 'a recent study has revealed that vision can be radically altered by sound in a non-temporal task, even when there is no ambiguity in the visual stimulus' [Calvert et al, 2004, p.32]. Therefore this research has tested audio visual aspects of art practice, mainly how differing auditory experiences affect the viewer's interpretation of painting as well as expand the painting itself. Time and space within sound are extremely 
closely linked as temporal aspects inform our spatial understanding and vice versa. This is particularly evident within anechoic and reverberation chambers where there is an extreme difference in reverberation times and physical features of the space.

When one listens to a sound from one source in an enclosed space a combination of the direct sound coming from the source together with the sound that is reflected off of all the surfaces in the room i.e. floor, ceiling and walls, as well as any objects is heard. The direct sound is heard first as it has the shortest path to travel, shortly afterwards the first reflection from the nearest surface is heard, then the second reflection and so on. These reflections make up the reverberant sound field. If the sound from the sources is continuous the reflections add together until the reverberant field reaches a pedestal level, normally after one or two seconds. If the sound is switched off the reverse happens i.e. the direct sound is lost first, then the first reflection, second reflection etc. until the sound level has dropped effectively to zero. The time that the sound takes to die away is referred to as the reverberation time and is arguably the most important acoustical characteristic of a space. The reverberation time is dependent on the size of the room and the total sound absorption of the wall, floor and ceiling surfaces. Soft materials like foam have very high absorption rates, whilst hard materials like marble have very low.

In this study installations have been set up in two extreme contrasting acoustic spaces namely anechoic and reverberation chambers; these are standard test spaces in acoustics laboratories. In an anechoic chamber the walls, ceiling and floor are all lined with foam wedges, which produce virtually no reflections, hence the name an-echo-ic. Reverberation times in high specification anechoic chambers are generally too small to be measured and on entering such 
a chamber one is struck by the feeling of extreme silence and deadness. John Cage draws attention to this extreme experience of going into an anechoic chamber:

'I entered one at Harvard University several years ago and heard two sounds, one high and one low. When I described them to the engineer in charge, he informed me that the high one was my nervous system in operation, the low one my blood in circulation. Until I die there will be sounds. And they will continue following my death' [Cage, 1961, p.8].

When one enters an anechoic chamber an awareness of oneself and ones physical presence and surroundings is often induced. See here the artwork The National Apavilion of Then and Now (2011) by Haroon Mirza, where he uses sound and light within an anechoic chamber to create an intense sensory experience. In Mirza's piece the viewers' awareness of the surrounding sound and vision are magnified through entering the space and Mirza's interest in physical aspects of the media he is using is exemplified. This allows for immersion in a phenomenological sense, as in Maurice Merleau-Ponty's focus on the subjective bodily experience in Phenomenology of Perception, 1962. The specific visual or aural sensory experiences are highlighted and are read in conjunction with one another, with little extraneous influences because of the physical attributes of the space.

The diametrically opposite extreme enclosure is the reverberation chamber in which all the surfaces are highly reflective. The walls and ceiling are sloped so that there are no parallel surfaces which would cause resonant standing waves, which would in turn produce patterns of high and low intensity sound. Reverberation times can be extremely long in reverberation 
rooms, typically eight or nine seconds. The reverberation chamber encourages homogeneity of sound levels within the space as the reverberation time is extended.

Although these chambers are not sounds in their own right they are acoustic environments that impose a set of conditions. One of the key benefits of using these spaces is that extraneous or external sounds or visual stimuli are limited therefore the focus is drawn to the visual and sonic. In much the same way that a gallery imposes visual restrictions, often being white or sometimes dark for certain work, with specific lighting used to focus the visual, the anechoic or reverberation chambers regulate work acoustically.

\section{Research spaces}

Before developing the full public exhibition preliminary research was carried out using the anechoic and reverberation spaces at The University of Edinburgh. Here there was the opportunity to revisit, test and explore ideas further within the same space. Initial findings led to a deeper focus on site specificity, with the importance of place as well as level of physical immersion of the viewer in the work being critical.

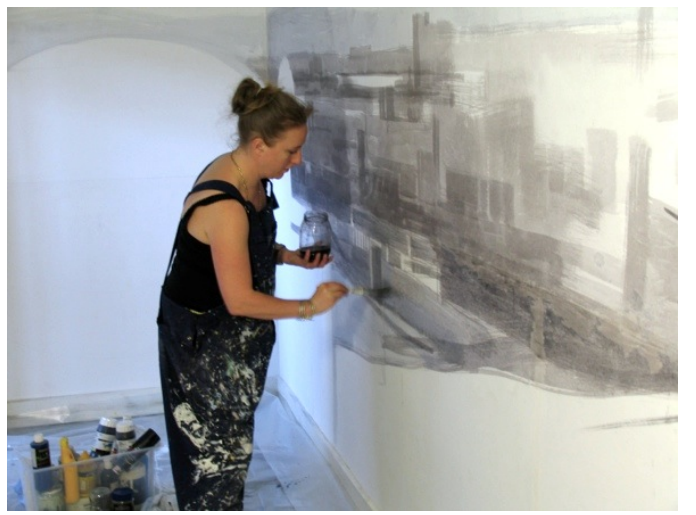

Developing a panorama in the reverberation chamber at The University of Edinburgh

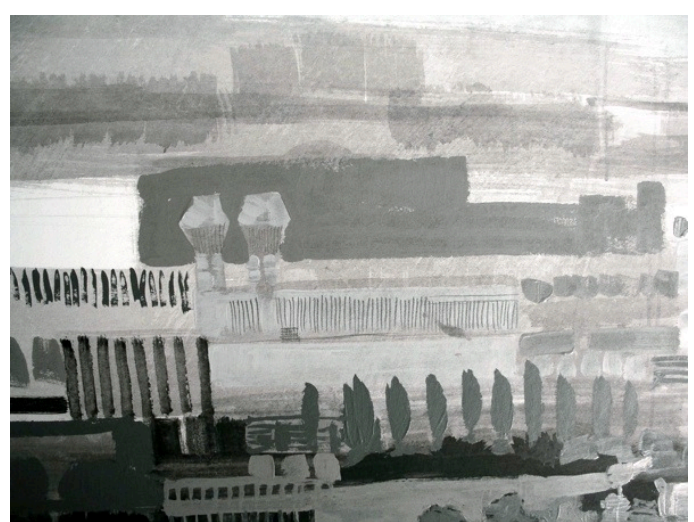

Detail of buildings as part a panorama in the reverberation chamber 
Placing sound within either chamber brings with it specific considerations. In the anechoic chamber the sound can be isolated because of the dead acoustics of the space. There is very little reverberation therefore you hear virtually pure sounds consequently the sound can be very carefully controlled and directed within the space. The reverberation chamber is the opposite as sound is verging on uncontrollable within it. The sound waves continue to reflect off the hard surface walls until they eventually fade. This means that the spatialisation within the sound does not come into play because of the natural reverberation of the room. The direction of the sound is lost and an array of signals coming from different directions is heard. The architecture of the space therefore dictates the sound quality and how it is perceived.

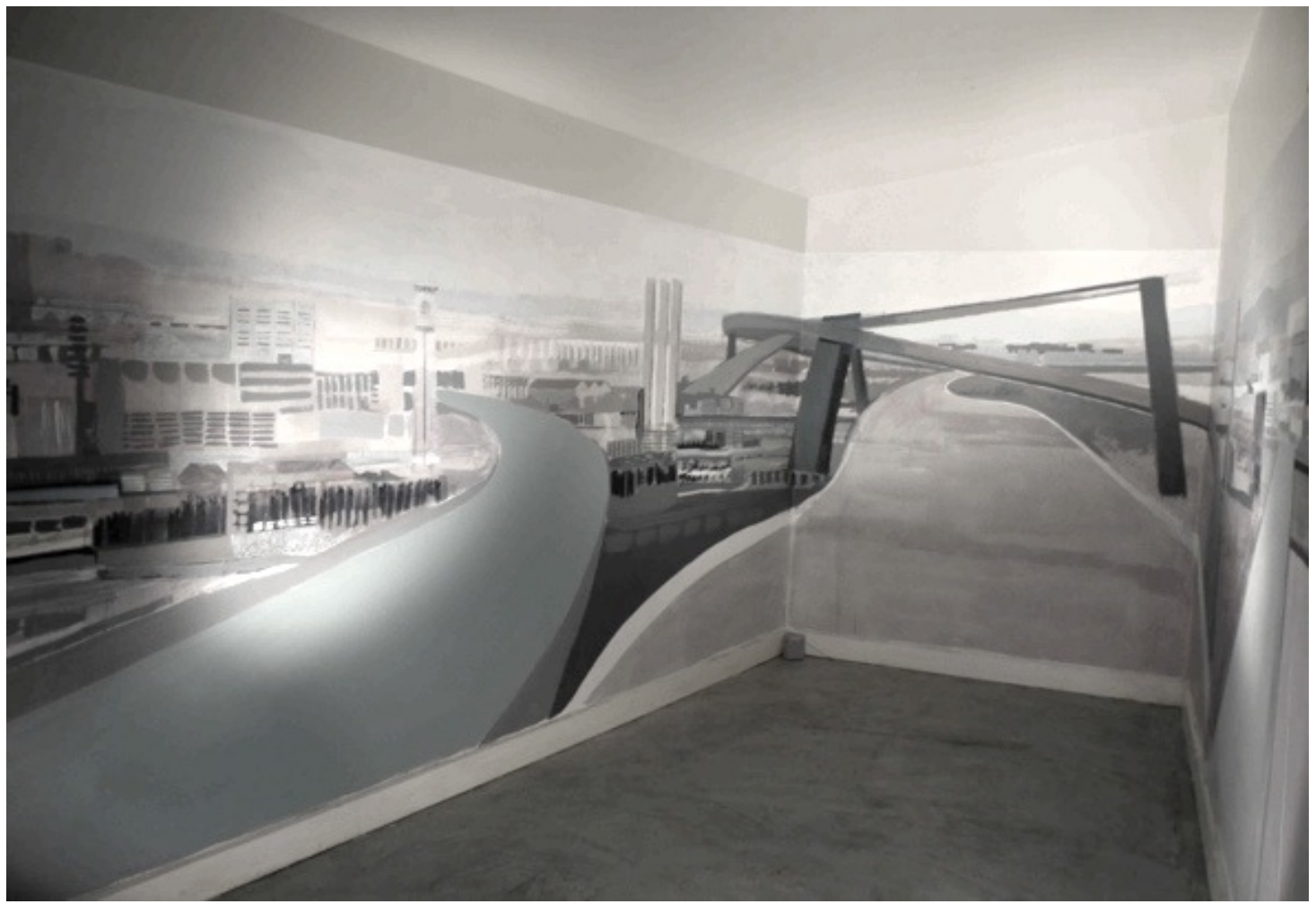

Experimental panorama in the reverberation chamber at The University of Edinburgh depicting scenes of Glasgow

In the reverberation chamber a panorama was painted onto the perimeter. It was a fifteen metre long wall painting, completely surrounding the chamber, built up with a limited palette 
of ink and gesso washes, with layers of acrylic paint and ink. The images were of Glasgow and the M8 motorway, with buildings and roads dominating the cityscape. The composition had varying focal points with some intimate, close-up areas and others fading into the distance. The overall impression was a mash-up of a city with the viewer submerged in that context. The soundscape echoed this rather dystopian environment with overlapping sounds of traffic resulting in specific cars or lanes of traffic coming in and out of focus, reverberating around the space. A point to note is that when stereo speakers are used in a reverberation chamber they are effectively working as surround sound as the reflections from the walls create a natural three-dimensional sound effect. This does not happen in most rooms or acoustic environments.

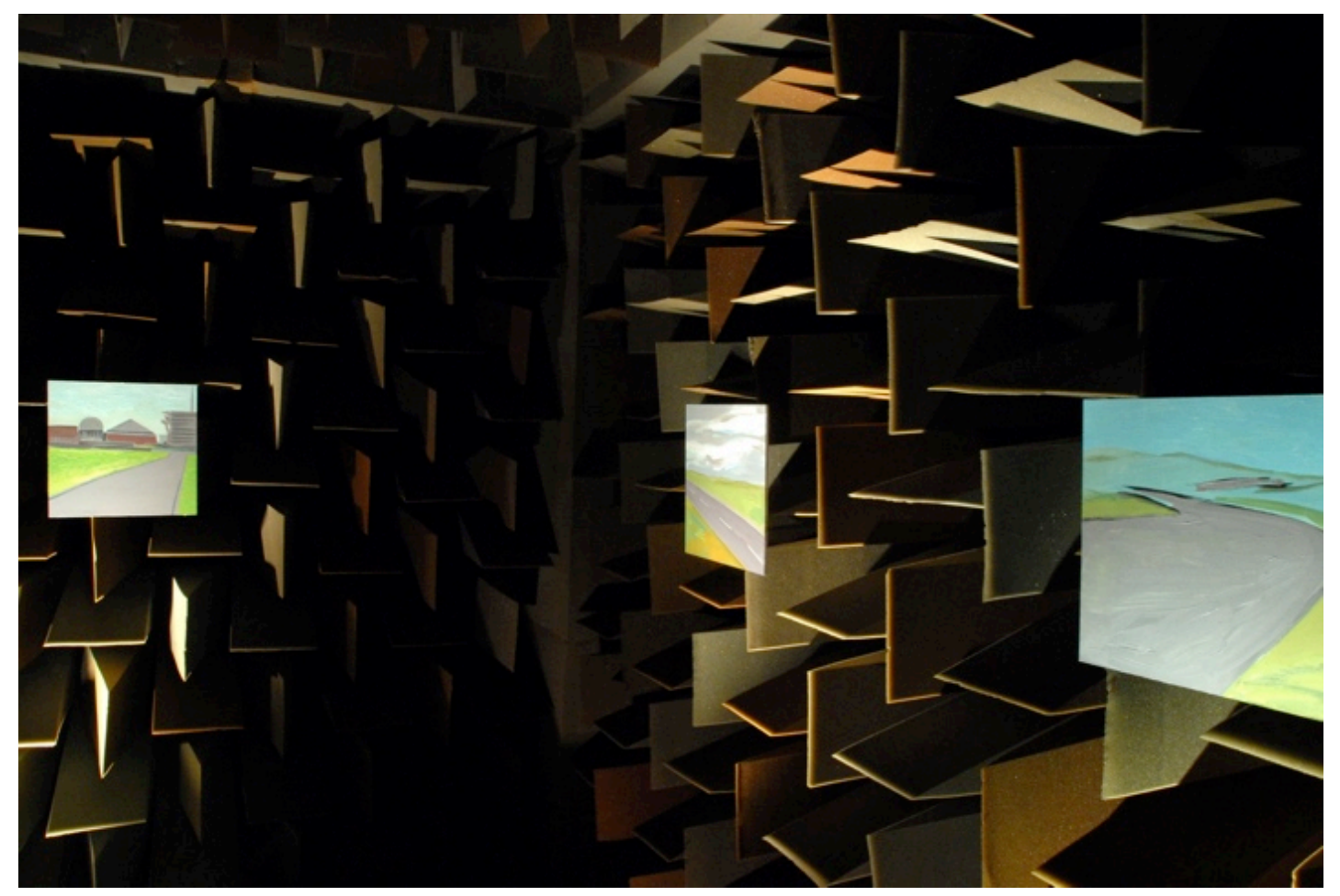

Developmental installation in anechoic chamber in The University of Edinburgh

The second part of the work was in the anechoic chamber which was almost completely silent 
with the walls, ceiling and floor made from foam wedges absorbing the sound. In addition the foam was dark in colour so the overall light level was very low, even given the lighting. The paintings in the anechoic chamber followed the same theme as in the reverberation chamber, with the city being the focus, but were much smaller and placed at specific isolated points around the walls. The soundscape in this chamber was made up of discrete traffic sounds, which occurred suddenly and were dispersed between significant gaps of silence. The speaker system was arranged so that the sounds appeared to come from different directions thus creating a spatial analogy between sound and vision.

Each room had its own soundscape that related to that particular painting installation however different ways of introducing sound to the rooms were experimented with. Viewers were invited to experience the paintings with no soundscape, the soundscape being introduced through a loudspeaker system and through headphones. A formal evaluation was carried out afterwards. The evaluation took the form of a questionnaire that gathered information about the viewer experience. Discussions were also held with a number of advisors such as other artists and related academics. The experiments were as follows:

1. Image with no sound

2. Image with sound played through speakers

3. Image with binaural recording headphones.

\section{Preliminary Exhibitions}

The outcome of these experiments was that the sound, and the way it was introduced to the space, clearly altered the experience of viewing the work. However the feedback identified great differences perceived by the different forms of sound transmission. For example, 
binaural recordings played through headphones were very effective in recreating realistic sound however the benefit of this in comparison with speakers was unclear. Although binaural recordings create a convincing sound experience, the sound is fixed to the viewers' direction therefore it changes as they turn their head or move through the work. With headphones the sound environment tracks the viewer, keeping the reality of any movement from the original recording, but not of the viewers' interaction with the space itself. This was felt to be too directed and not reflective of the visual work, which the viewer has to move into and through. The integration of sound and image within the work is more effective when the two elements are in tandem with each other. This was achieved most cohesively when the sound was played through the speakers, with both visual and audio elements being three-dimensional, surrounding the viewer in the space. The synthesis of these elements created an overall environment for the viewer, as was confirmed through viewer's comments. The use of binaural recordings and headphones more generally have much potential and have continued to be experimented within the research but as sound pieces in their own right.

\section{Dead or Alive exhibition}

The primary public exhibition Dead or Alive was held in the extreme sonic environments of the hemi-anechoic and reverberation rooms at the National Physical Laboratory London. The exhibition took the form of installations consisting of paintings and soundscapes set up in two adjoining spaces, a hemi-anechoic chamber (dead) and a reverberation chamber (alive). A new body of work was made including a twenty-seven-metre panoramic painting, a series of small paintings and two surround soundscapes. The exhibition spanned these two rooms, the first one being a five-sided reverberation room, with a decay time of over ten seconds, the second room being a hemi-anechoic room with background sound levels being close to zero decibels. Entering the first space the viewer was encircled by a large panorama accompanied 
by a relentless montage of environmental noise. In the second space there was a much greater temporal separation of the sounds and the images were in the form of small individual paintings placed around the wedge-lined walls.

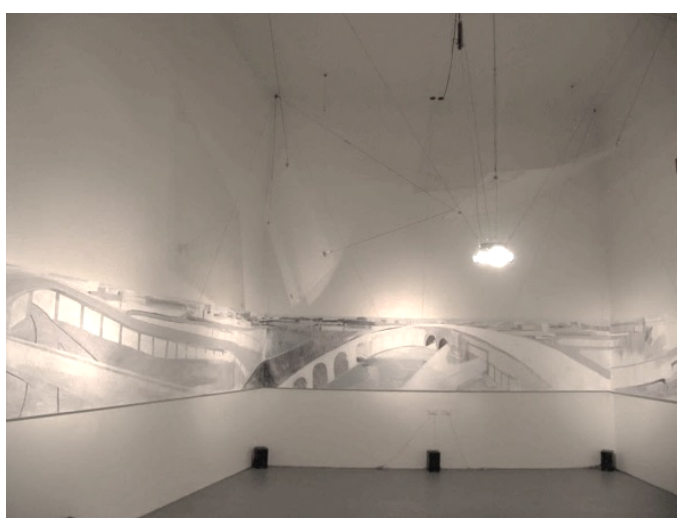

Panorama in the reverberation chamber at the National Physical Laboratory, London

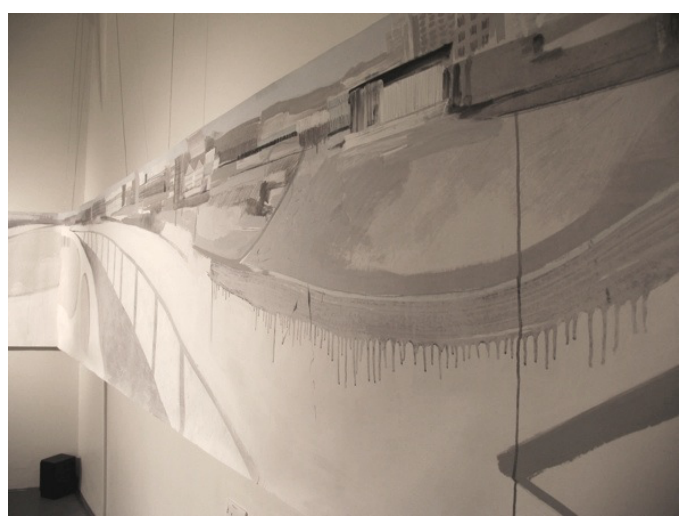

Detail of the panorama in Dead or Alive exhibition

In a full anechoic chamber (like the one at The University of Edinburgh) the walls, ceiling and floor are lined with foam wedges to absorb the sound and it is necessary to walk on a grid when inside. This is inconvenient for large experiments and indeed for exhibition displays, hence the idea of the hemi-anechoic chamber in which the floor is flat and only the walls and ceiling are lined with foam wedges. The characteristics of a hemi-anechoic chamber are not as good as a full anechoic chamber but are usually more than adequate for most practical purposes.

Although similar core material was used to create the sound and visual imagery for the two rooms the experience in each was dramatically different. The soundscapes were made up from field recordings, mainly of traffic noise, edited to produce surround sound in 5.1

configurations. The raw sounds were mostly recorded in Glasgow where the motorway passes directly through the city centre, and the visual imagery related to the same traffic, motorways and urban city sprawls. In reality the reverberation chamber was extremely oppressive due to the continual din of the soundscape reverberating around the room. This was powerful to 
experience but being in the space with the work could not be maintained for long periods. The hemi-anechoic chamber was also stifling but seemingly because of the clarity of the silence.

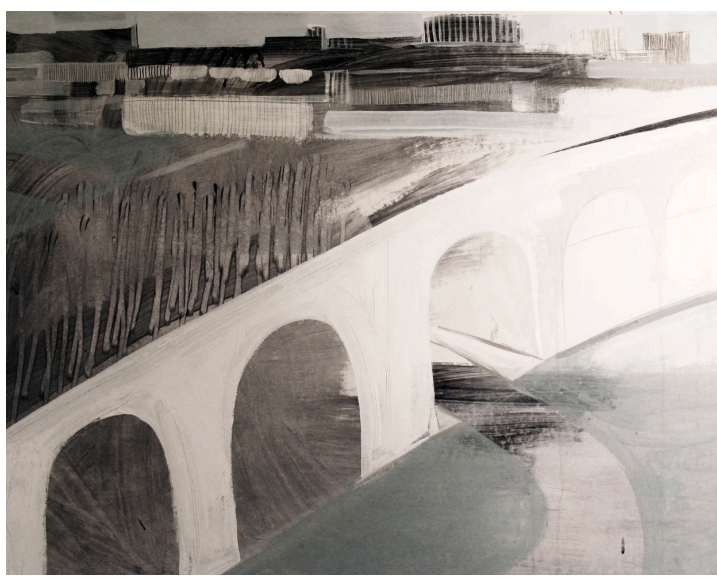

Detail of painting in Dead or Alive exhibition

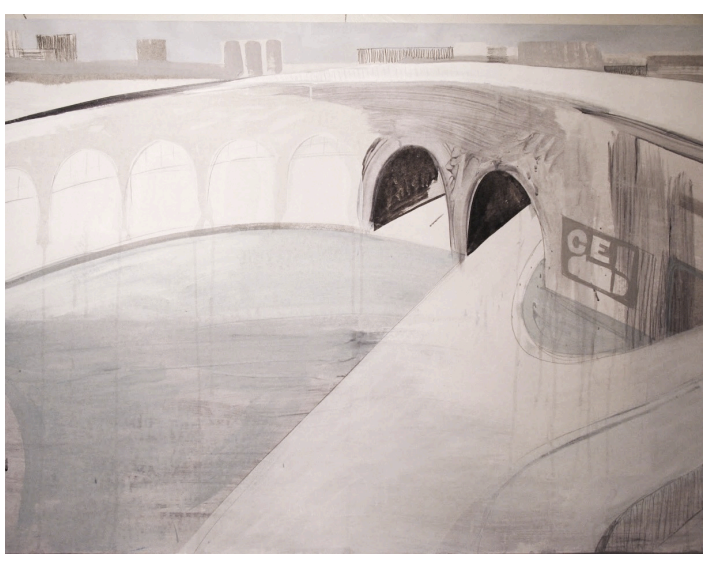

Detail of bridges and roads in Dead or Alive exhibition

One rather unexpected aspect of the work was that the oppressive nature of the spaces themselves became key to the work, which resulted in varying implications for future works. On one hand the work surrounding the viewer was key however, there was a risk of the space itself becoming so dominant that the visual and sound works could be secondary. It was also the first point at which the idea of creating an independent chamber for the work was considered, which later became part of the work itself.

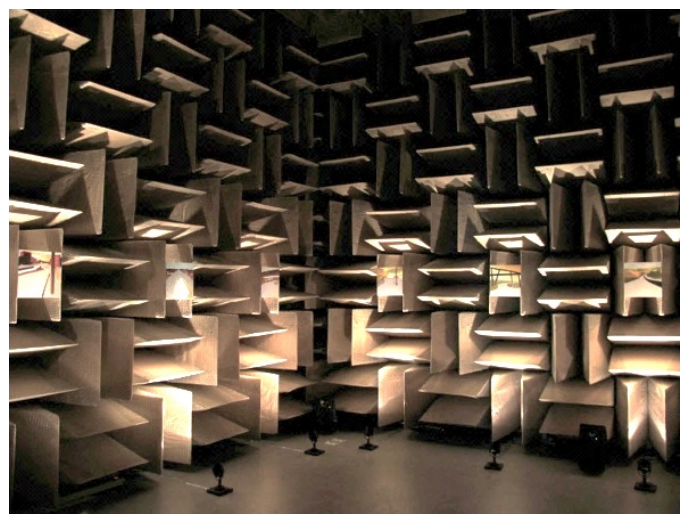

Anechoic chamber installation as part of Dead or Alive exhibition

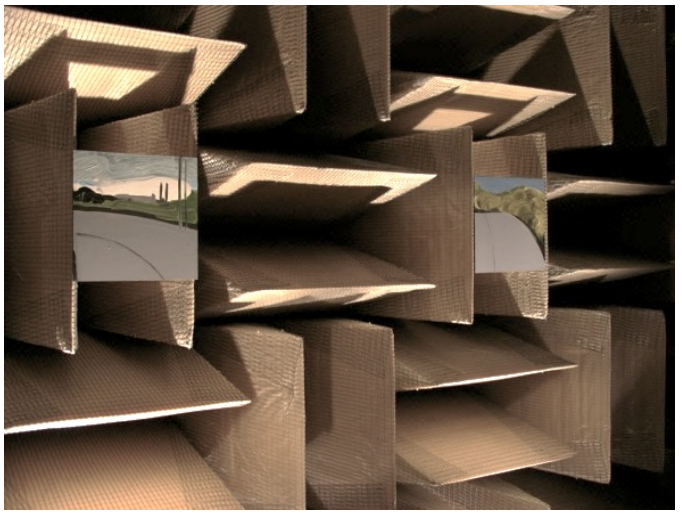

Detail of anechoic chamber installation as part of Dead or Alive exhibition 


\section{Evaluation}

In order to help evaluate the impact of the two contrasting rooms on viewers over thirty members of the general public who had visited the exhibition were asked to fill in detailed questionnaires. The majority of these people said they had not been to a similar exhibition before but some were familiar with the work of other artists working with sound e.g. Laurie Anderson, John Cage, Steven Reich, Brian Eno, David Cunningham, Bill Viola, Bruce Nauman and Janet Cardiff.

More than half of the viewers liked their experience of being in the panorama installation in the large reverberation chamber although almost as many were unsure. Some felt the experience rather overwhelming and felt imprisoned. 'As an experience of a cold bleak industrial landscape it was depressingly lonely'. Two viewers said it made them feel as though they were in central London 'very busy with lots of people around and pollution', 'noise and confusion'. In response to a question about the panorama surrounding the viewer nearly all the viewers responded positively, remarking that the experience was richer when the viewer felt as if they were within the painting. One remarked 'why don't we have more totally immersive artwork?' It was also commented that the surround sound 'changes your emotions to a lively feeling'.

When asked about their experience in the hemi-anechoic chamber typical comments were that it helped to create an 'illusion of silence' and that 'it changes your feelings a bit more than you would expect'. The main reservation was that some people had expected the paintings to be larger although as one said ' I was expecting them to be bigger before I went in but felt the size was appropriate for the different sound'. One person felt that the impressiveness of the room itself overshadowed the paintings. The responses pointed to a 
general feeling of space which contrasted with the intimacy of the room 'Relaxed, peaceful and slightly lonely, as if in the countryside with no one around for miles'. One viewer remarked 'Initially a feeling of cosy comfort, warm and nurturing, this changed after a while to feel rather oppressive'.

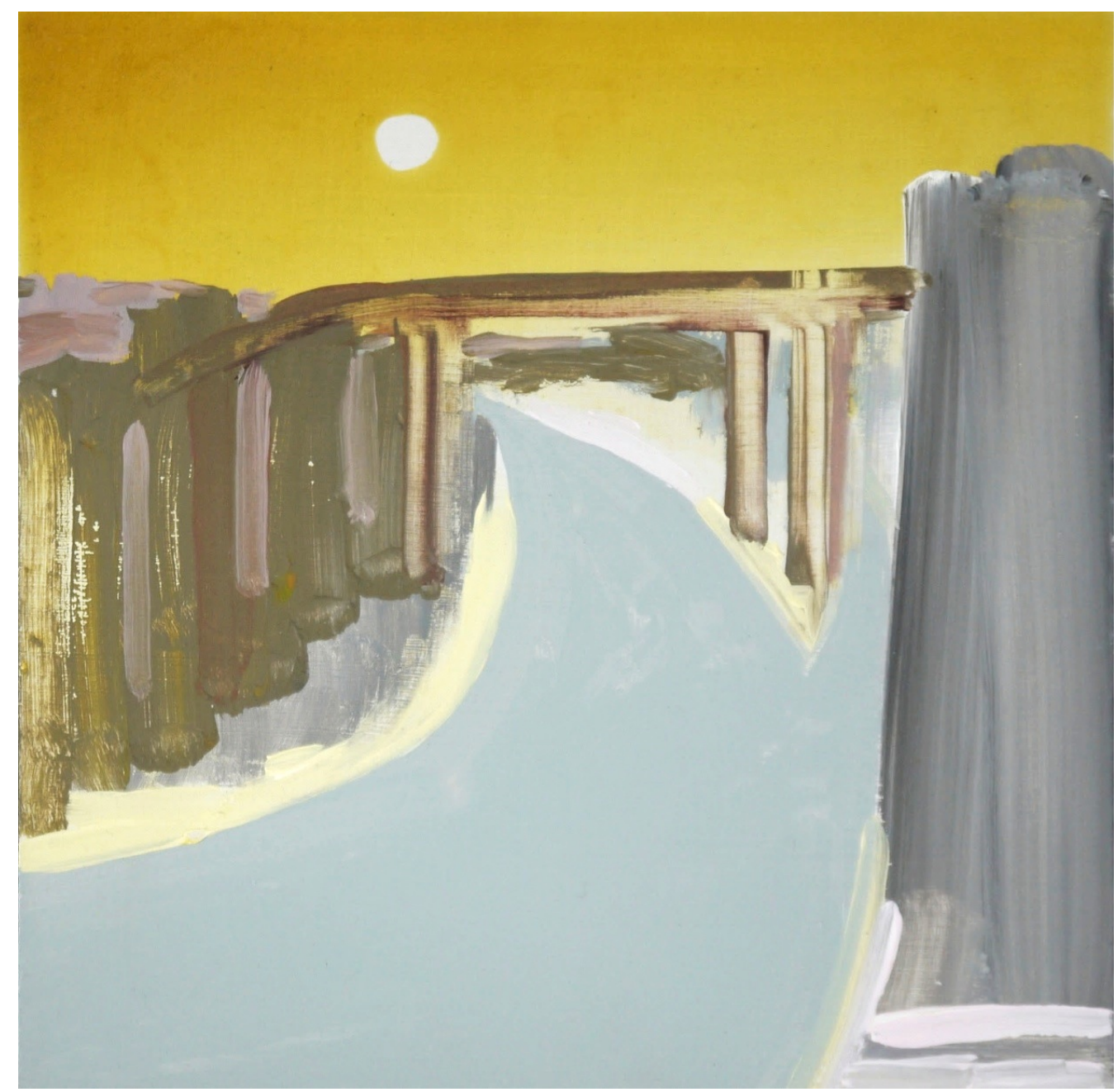

Sunset Bridge, painting in the anechoic chamber as part of Dead or Alive exhibition

When asked about their experience in the hemi-anechoic chamber typical comments were that it helped to create an 'illusion of silence' and that 'it changes your feelings a bit more than you would expect'. The main reservation was that some people had expected the paintings to be larger although as one said 'I was expecting them to be bigger before I went in but felt the size was appropriate for the different sound'. One person felt that the 
impressiveness of the room itself overshadowed the paintings. The responses pointed to a general feeling of space which contrasted with the intimacy of the room 'Relaxed, peaceful and slightly lonely, as if in the countryside with no one around for miles'. One viewer remarked 'Initially a feeling of cosy comfort, warm and nurturing, this changed after a while to feel rather oppressive'.

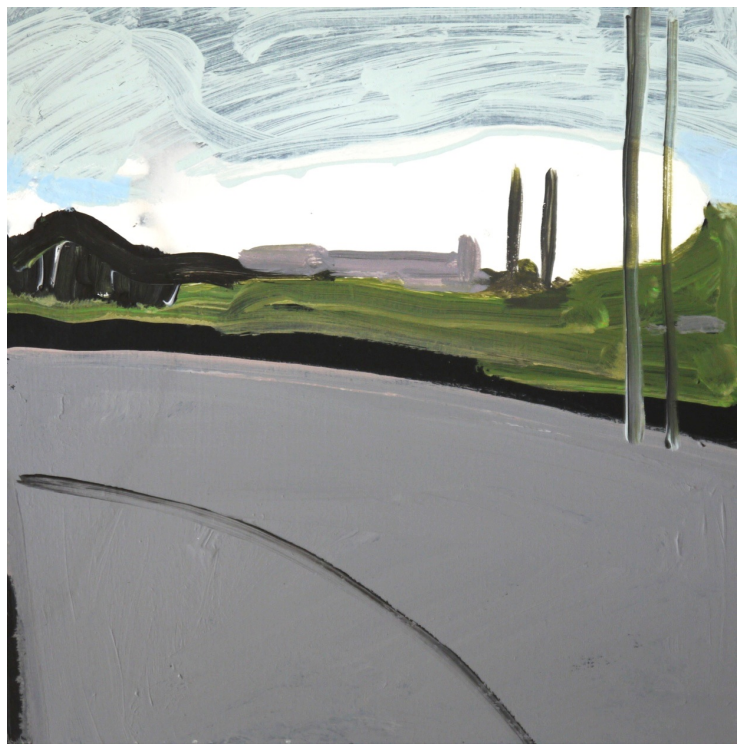

Winter Sky, painting as part of Dead or Alive exhibition

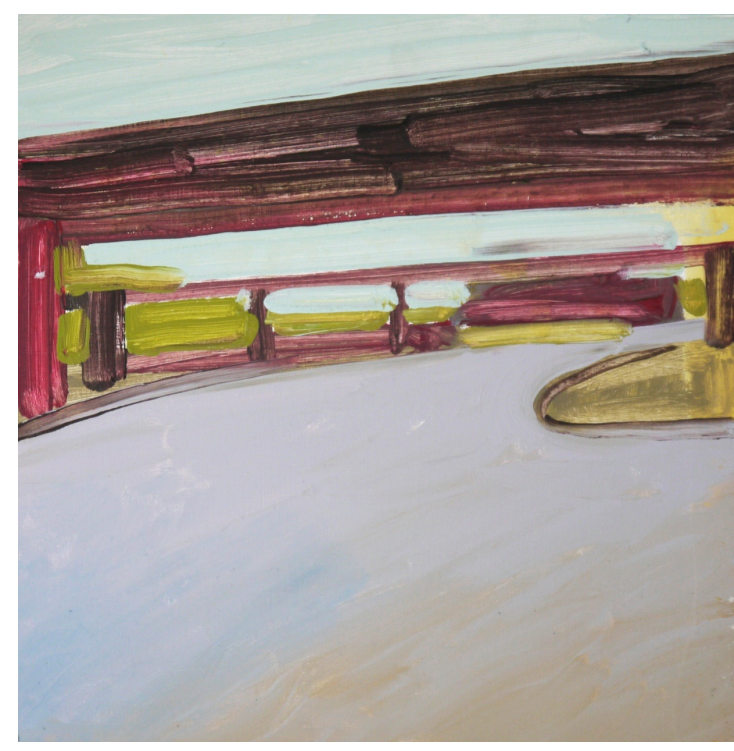

Purple Bridges, painting as part of Dead or Alive exhibition

In summary the prevailing view was that the sonic and visual worked together to create an atmosphere which encouraged you to think more about the paintings. Nearly all people felt that the soundscapes affected the overall impression of the paintings, 'adding an extra dimension which brings the artwork to life' and 'makes you feel in the painting'. Analogy was drawn with the film-soundtrack which can change the impression given by the visual track alone. The reverberation room was generally portrayed as being 'confusing and sinister' with the continuous and overlapping sound making people feel stressed and anxious and uncomfortable. One person said 'this is London, get me out'. This contrasted with the hemianechoic room which gave a feeling of peace and calm. 'I felt like I was in a vacuum of silence, peaceful and calm' said one person. Moving from one room to the other left some 
people disorientated; they found the hemi-anechoic room disconcerting, especially in the quiet pauses of sound. Overall there were many positive comments such as 'I loved both rooms' and 'helped imagine I was in the picture'.

\section{Three propositions}

Throughout the study the idea that sound alters the interpretation of painting has been explored. Not only does painting command its own presence through sound but it also responds to the addition of sound. Controlling the sound environments or adding sound has an impact on the meaning of the work and of painting itself.

There are three propositions suggested through this line of enquiry, the first one (sound) being that the sound environment of a painting affects, and potentially enhances, its reading. The second (vision) is that painting itself can be transformed through this central tenet, and that in this case the format of the work has shifted to respond to the sound. This is where the panorama or the idea of an all-encompassing environment emerges. The third (immersion) is that the installation of these together results in something more than the sum of the parts and produces an immersive environment, which expands the scope of the painting. Development of these propositions was carried out through research in extreme sound environments. Here the specific acoustic properties of the spaces changed and transformed both the visual and sound work, altering the interpretation of the work. Looking at each of these aspects in more detail, it has been possible to assert the following.

That an artwork will be viewed in an isolated quiet space is often assumed with background sounds often thought of as distractions. Painting's sensorial context, in this case the sound 
environment, is normally overlooked in the analysis or understanding of work. The author has explored the background sound of painting installations by utilising the ambient sound of a site such as Panorama, 2010, where the loud background street noise overlapped with the added soundscape. However the research here seeks to control the sound environment by utilising specific acoustic chambers and adding sound to them. Relatively little research has been carried out in this area in regards to painting and sound. Existing research in this field has mainly explored painting's relationship with music, as opposed to its relationship with its own sound environment or indeed environmental sounds being incorporated into the showing of painting. There are interesting examples of the environmental sounds being introduced to paintings, such as David Toop's soundscape for A Peepshow with Views of the Interior of a Dutch House by Samuel van Hoogstraten's (1655-60) or Chris Watson's accompanying sound to The Cornfield by John Constable (1826). However these are sonic responses to historic paintings which reimagine the sound environment rather than utilising the current one.

With context being central to our understandings of art, the sound environment that we experience art in cannot be ignored. Rather than being subsumed in a pluralistic context, painting and its sonic environment, through the use of specific sound conditions or addition of sound, can be identified or employed as a specific way of working with sound and vision. The way we experience a painting through our senses directly affects the way we interpret the work. Recognising and understanding the sound environment allows space for further development of painting in an expansive way, opening up possibilities within the surface, image, space and time narrative. Sound and visual work can create intense experiences for the viewer, such as in the work of Haroon Mirza where both sound and visual elements are united. The similarities in fundamental scientific properties of both sound and vision, such as 
their wave-like phenomena, synthesis and spectra, means that their interpretation can be closely linked. As well as their scientific properties, these stimuli are also culturally and psychologically related, giving an increased potential for the artist to utilise their relationship and allowing for transformations to happen between the two. With sound now permeating contemporary art and indeed being a form of contemporary art in its own right, the specific relationship between sound and vision is increasingly important.

Through the research the impact of sound on the painting has been varied in form and identification. It has resulted in the consideration of both the acoustic environment with incidental sound and the addition of controlled sounds, in the form of diegetic soundscapes relating to the paintings, such as the sound of traffic where the painting has roads. With the introduction of sound to the visual work items were introduced that were not present in the paintings. The parameters of the painting were changed, the most obvious being the increased role of time within the work therefore temporal and durational elements had been necessitated in the visual experience. When another stimulus, in this case sound, is added to the two-dimensional image, additional subjects within the work are enabled. For example, the performance or music alongside paintings by Jutta Kouther allows for the work to take on a number of strands of meaning and interpretation within the same installation. The sound adds layers of interpretation and meaning that do not exist within the paintings, therefore the work has components that are not visible in the painting.

The second proposition in the research (vision) is that painting itself can be transformed through its relationship to sound. Not only is the sound an aspect of the visual works' formal or physical qualities and environment, it becomes instrumental to the interpretation and 
therefore the making of the work. During the research period the painting changed as a response to the use of sound and the format of the work shifted. Paintings started as individual discrete paintings, with the framing of each image limited to the edges of the canvas, and transformed to horizontal format images that surround the viewer. The framing of an image (an extreme example being the diorama) fixes a viewpoint and places the viewer outside of the work, looking in. See for example the shift in the work of Op de Beeck between his dioramic work to his more encompassing panoramas and walk-in environments. In the case of this research the viewer physically enters the frame and is embedded within it. There is a shift that happened within the work, from the paintings being viewed as twodimensional, with space coming through the image in terms of an illusion or pictorial space, to one that the viewer can no longer see in one view, enters and is engulfed by. The painting, using the panoramic format, takes the image beyond the viewer's gaze and encompasses them within the work.

The paintings changed form in response to the parameters set by the sound, which led to the desire for the paintings to be entered rather than be viewed from a fixed point. The perspective of the viewer changed to one of being literally within the painting. The emergence of the panorama, or panoramic style installations, allowed the sound to be complemented in the visual realm, not as a copy but rather as a visual echo. The painting took on the idea of a sound or visual field, the principals of which are inherent to a sonic experience where the sound surrounds the viewer. This shifted the painting from a one-focus work, or even a multiple focus image, to one that encompasses the viewer within it. Rather than viewing the work through one lens or viewpoint the viewer becomes immersed within the painting experience. Traditional panoramas were based on a fixed viewing point designed to be seen from a central viewing platform. However the paintings in the research have 
multiple foci, changing scale and ambiguous perspectives due to their amalgamated, collated imagery.

There is an inherent element of time within the act of viewing however painting has often been seen as a snapshot of a moment that the viewer has one perspective on. This focus on the presentness of painting is particularly evident within Modernist thinking where a painting is considered instantaneous and out-with time considerations. In Art and Objecthood Michael Fried describes this immediacy within modernist work as, 'at every moment the work itself if wholly manifest' [Fried, p.167]:

'It is above all to the condition of painting and sculpture - the condition, that is, of existing in, indeed of secreting or constituting, a continuous and perpetual present that the other contemporary modernist arts, most notably poetry and music, aspire' [Fried, 1998, p.167].

This view of painting has been surpassed by a wider view of a more emboldened painting, which can be expanded beyond this snapshot in time and presence. Time and a further durational element to how we view a painting can be valuable in opening up the possibilities that painting provides. Within the research we have explored different aspects that introduce time. There are the soundscapes themselves, being durational and ongoing, some of which have a beginning and end and some of which are continuous or ambient background sounds. Secondly there is the changed format of the work, to a long panoramic form that encourages a horizontal, spatial and physical reading in time. There is also a third aspect of time, which comes through the content of the work: the images in the paintings are of real places that can be activated through the time continuum that sound enables. 
The introduction to Vitamin $P$ discusses the more expanded position of painting today, stating that:

'Contemporary painting contends that art is not one thing and that therefore no one way of looking is sufficient; one must always be prepared to add new aesthetic axioms. That is one reason some of the painting in this volume keeps refusing its own self-containment ... It is precisely through this call for flexibility over commitment that contemporary art (of which painting is just one part) claims a higher degree of self-consciousness than Modernism’ [Schwabsky, 2002, p.8].

The inclusion of other media, forms, technologies, histories and so on to the realm of painting is part of its current status. The research has proposed that the addition of sound brings particular qualities of time and three-dimensionality that have not only changed the paintings themselves but have maintained the distinct qualities of sound and painting to create a different way of viewing painting. In Painting in An Expanded Field, Fares discusses the previous limitations of painting, one of which is that painting is normally considered strictly non three-dimensional [Fares, 2004]. He argues for a broader understanding of painting, not that 'anything goes' but that other dimensions and aspects to the work can strengthen and serve the purpose of painting, noting 'these new ways are not, however, opposite to painting but, together with painting, are part of an expanded field as it has developed historically ...' [Fares, 2004, p.485]. The addition of sound has led to a rethinking of painting and the viewer's relationship with it. Painting is not a static entity but one that changes through its relationship with sound, time, space and the implication of movement inherent to it. 
The third proposition around immersion is the key to the installations, taking on the results of both sound and vision and their effect on the making and viewing of the work. No longer does the work invite a visual experience that the viewer can choose to look at (or not) depending on their gaze, but it demands that the viewer becomes immersed in the work. The viewer physically enters the space and is surrounded both visually and aurally; it envelops the viewer. They must physically enter the space and move within the work, therefore the viewer is active within the work. Once the viewer enters the chamber they are encompassed within it, to the extent that in some cases the viewer's own body affects the acoustics, the sound they experience and their interpretation of the work. The work itself is changed by the viewer entering the space, encouraging a phenomenological engagement with the work. The viewing becomes an experiential activity, purposely making the viewer aware of their physical self and their surroundings. The sound moves around the space, the visual work requires movement to be viewed fully and the viewer is forced to be mobile by the nature of the space, even if merely to enter and exit.

\section{Conclusion}

Extreme sound environments have been used in this study to push the relationship of sound and painting to its limit. The anechoic and reverberation chambers allow the sound environment to be considered and controlled to maximize the impact of the surroundings. Because of their specific acoustic qualities the chambers helped to focus the potential of the sonic environment of painting. Therefore two aspects of the sound were tested, the reverberation of the environment as well as the addition of sound. The extremities of the chambers themselves gave certain oppositional experiences, one silent, very controlled and acoustically dead, and the other a noise field. These added to the complexity and the experience of the paintings. 
The viewer walking into the space of the artwork, the addition of a sound environment and the use of extreme acoustic spaces all highlight the physicality of the viewer, thus the focus of the painting is shifted away from image or illusion to one of viewer experience. In an interview about the Soundings exhibition in Museum of Modern Art, NY [London, 2013] the curator Barbara London talks about the viewers' relationship with the work, discussing that viewing work is a continuum:

'The audience can be observers, or listeners, but they really have to move around in order to fully experience the work' [in Eppley, 2013, p.4].

She finishes the interview talking about the capacity of sound to construct experience. Thus the very nature of the sound enables an experiential quality that can enhance and expand the scope of visual work, in this case painting.

The process of the research has led to a literal and physical shift in the work as well as the thinking around it. From the paintings being flat static objects they spilled over their own frames and expanded their flatness to encompass time and a three-dimensionality. This development happened through the process and engagement of sound. The changing format of painting through the introduction other media is evident in painters working in an expanded field such as Victoria Morton, where the physicality of her painting installations respond to and reference sound, or the animated works of Katy Dove. The work emerged by understanding the temporal and physical qualities of sound and the traits that are specific when sound and vision are brought together. The painting was expanded not by merging these discrete elements into one hybrid or emulating each other but by bringing together two distinct forms of work, painting and sound together. 
Throughout this study the focus has been to identify and enhance the viewing experience of painting in relation to sound. Both the sound and the paintings have transformed through the process and their relationship to one another. A different artwork has emerged, taking on the expanded nature of contemporary painting and embracing sound and the sonic environment within that. The shift has led to all-encompassing installations which not only are within the realms of painting but take advantage of how the painting can be altered and enhanced by its sonic environment.

\section{Acknowledgements}

With thanks to The National Physical Laboratory, EPSRC, The University of Edinburgh and The Glasgow School of Art. Also to Professor Andrew Patrizio, Professor Neil Mulholland and Professor Clive Greated.

\section{References}

Calvert, G., Spence, C. \& Stein, B.E. eds., 2004. The handbook of multisensory processes Cambridge, Mass. ; London: MIT Press.

Cage, J., 1961. Silence: Lectures and Writings, Wesleyan University Press.

Chion, M., 1994. Audio-vision : sound on screen C. Gorbman, ed., New York ; Chichester: Columbia University Press.

Eppley, C., 2013. Sound is Here: An Interview with Barbara London. Rhizome.org. Available at: http://rhizome.org/editorial/2013/sep/12/sound-here-interview-barbara-london/ [Accessed September 20, 2013].

Fares, G., 2004. Painting in the Expanded Field. Janus Head, 7(2 Open Issue), pp.477-487. 
Fried, M., 1998. Art and Objecthood: Essays and Reviews, University of Chicago Press.

Greated, M., 2009. The Nature of Sound and Vision in Relation to Colour. Inspiration for Design; Special Issue of Optics and Laser Technology.

Merleau-Ponty, M. 1962. Phenomenology of Perception. New York: The Humanities Press.

Schwabsky, B., 2002. Painting in the Interrogative Mode. In T. Bayrle, ed. Vitamin P. Phaidon, pp. 6-10.

Shams, L., Kamitani, Y. \& Shimojo, S., 2004. Modulations of visual perception by sound. In G. Calvert, C. Spence, \& B. E. Stein, eds. The Handbook of Multisensory Processes. Cambridge, Mass.: MIT Press.

Toop, D., 2010. Sinister Resonance: The Mediumship of the Listener, Continuum. 